\title{
Multi-physics evaluation of the steady-state operation of an Aqueous Homogeneous Reactor for producing Mo-99 for the Brazilian demand
}

\author{
Authors: D. M. Pérez ${ }^{1 *}$, D. Milian P. ${ }^{2}$, L. H. Pardo ${ }^{2}$, D. E. M. Lorenzo ${ }^{2}$, and C. A. Brayner de O. L. ${ }^{3}$ \\ ${ }^{1}$ Departamento de Energia Nuclear, Universidade Federal de Pernambuco (UFPE), Cidade Universitária, Avenida \\ Professor Luiz Freire 1000, CEP: 50670-901, Recife, PE, Brasil. \\ ${ }^{2}$ Nuclear Engineering Department, Higher Institute of Technologies and Applied Sciences (InSTEC), University of \\ Havana, Avenida Salvador Allende y Luaces, Quinta de Los Molinos, Plaza de la Revolución, 10400 Havana, Cuba. \\ ${ }^{3}$ Centro Regional de Ciências Nucleares (CRCN-NE/CNEN), Cidade Universitária, Avenida Professor Luiz Freire 200, \\ CEP: 50740-545, Recife, PE, Brasil.

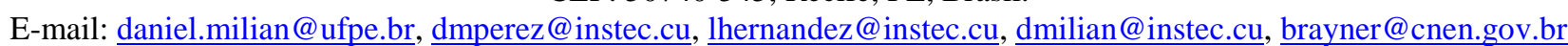

Received 20 September 2020, Revised 3 February 2021, Accepted 4 February 2021

\begin{abstract}
The studies summarized in this paper aims to predict the steady state operation of a low-enriched uranium fuel ARGUS type aqueous homogeneous reactor for producing ${ }^{99} \mathrm{Mo}$ to meet the domestic demand of Brazil through a coupled multi-physics (Neutronics + Thermal-hydraulics) evaluation. The coupled multi-physics evaluation included aspects related to the neutronic behavior such as fission induced energy deposition profile, medical isotopes production; and the thermal-hydraulic behavior such as temperature, velocities and gas volume fraction profiles. The methodology followed for the multi-physics and multi-scale coupling of the neutronic and thermal-hydraulic codes (MCNP + ANSYS-CFX), discussed in detail in this paper, represent one of the main outcomes of the current study. The methodology was tested for two different operating configurations of the ARGUS reactor, the original high-enriched uranium configuration used since 1981, and the new low-enriched uranium configuration after the conversion process during 2012-2014. The calculations carried out showed that the reactor, in the studied configuration, is able to produce 246.5 six days Curie of ${ }^{99} \mathrm{Mo}$ in operation cycles of five days. Which is equivalent to more than a third of the estimated Brazilian demand for 2025.
\end{abstract}

Keywords: Aqueous Homogeneous Reactor; Brazilian demand of Molybdenum-99; multi-physics; thermal-hydraulic behavior.

\section{Introduction}

The use of small aqueous homogeneous research reactors (AHR) for producing ${ }^{99}$ Mo could be an attractive alternative, compared to the traditional method of irradiating targets in heterogeneous reactors, due to their expected low cost (up to US \$ 30 million) ), small critical mass ( $\sim 10 \mathrm{~kg}$ of Uranium), inherent safety and simplified fuel handling, processing and purification characteristics. More than 30 AHRs have been built and operated over many years as research reactors. At the beginning of 2019 only two homogeneous liquid fuel reactors were still in operation, both in the Russian Federation [1]-[3]. In recent years the interest in the use of this technology for the production of medical isotopes has prompted several countries and the scientific community to initiate programs to evaluate its feasibility [1]. This interest has been reinforced as a result of a group of milestones.

(1) The consultants meeting held in 2007 with a team of experts engaged in the field of AHRs and radioisotope producers of which the [1] presents a summary of discussions and the technical presentations given by the participants. This meeting facilitated the exchange of information on the "state of the art" which resulted in an objective evaluation of the technological challenges and other relevant implications of the AHRs technology, especially in connection with the production of radioisotopes.
(2) The IAEA Coordinated Research Project (CRP) "Feasibility Evaluation of the Use of Low Enriched Uranium Fuelled Homogeneous Aqueous Solution Nuclear Reactors for the Production of Short Lived Fission Product Isotopes" [4]. The overall objective of the CRP was to encourage cooperation and foster exchange of information in the area of AHR, specifically on the use of low-enriched uranium (LEU) fuel and the production of short-lived fission product isotopes.

(3) The 2009-2010 global medical isotope supply shortages and the subsequent limited supply shortages which have continued to occur in 2013, 2014, 2015, 2017, 2018 and in early 2019 [5]-[7].

(4) A growing number of scientific papers on this subject each year, just to mention a few [8], [9], [18], [19], [10]-[17]. In addition, a significant number of technical reports, conference presentations and others are also evidence of the existing interest in this technology.

(5) The successful operation of one of the longest running AHR, the ARGUS reactor (Figure 1), a $20 \mathrm{kWth}$, highenriched uranium (HEU) solution reactor operated at the "Kurchatov Institute" since 1981 with great economic and safety indices. The success in the ARGUS conversion to LEU fuel [20], [21]. ${ }^{99}$ Mo samples produced in the ARGUS reactor were studied and was determined that they are radiochemically pure to European and US pharmacopeia standards [1]. The successes achieved by the 
ARGUS reactor technology led to the decision to construct a Proof-Of-Concept production site based on the ARGUS operational experience in Sarov [22] and to restore the Argus-FTI (at the Umarov Physical and Technical Institute in Dushanbe, Tajikistan), to be operational in 2020, with Russian assistance under financial support of China [3].

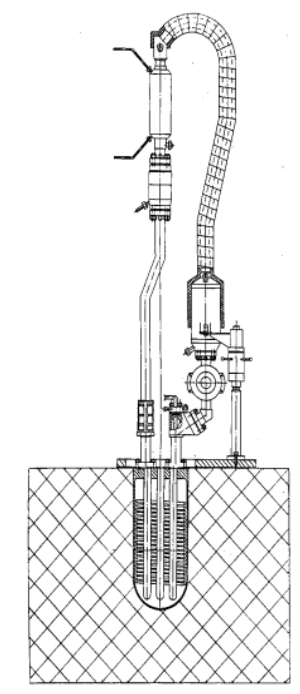

\section{Figure 1. Scheme of the Russian ARGUS reactor [20].}

This paper aims to predict the steady state operation of a LEU fuel ARGUS type AHR for producing ${ }^{99}$ Mo to meet the domestic demand of Brazil through a coupled multi-physics evaluation. To fulfill this objective, a methodology was developed for the multi-physics and multi-scale coupling of the neutronic and thermal-hydraulic codes. The developed methodology, which represent one of the main outcomes of the current study, allows the coupling of the computational codes MCNP6 (for the neutronic calculations) and ANSYSCFX 19 (for the thermal-hydraulic assessment) using "homemade" codes for the pre-processing and post-processing of the main codes. The coupled multi-physics evaluation included aspects related to the neutronic behavior such as fission induced energy deposition profile, medical isotopes production, uranium consumption, plutonium production, kinetic parameters; and the thermal-hydraulic behavior such as temperature, velocities and gas volume fraction profiles. The methodology was tested for two different operating configurations of the ARGUS reactor, the original HEU configuration used since 1981, and the new LEU configuration after the conversion process during 20122014.

\section{Methodology}

\subsection{Brazilian demand and AHR thermal power}

In 2017 the medical activities in Brazil consumed 4\% of the worldwide demand of ${ }^{99} \mathrm{Mo}$, representing 370-380 six days Curie per week, with an estimated increasing in the demand of $8 \%$ per year [23]. That implies that currently, by 2020, the domestic ${ }^{99} \mathrm{Mo}$ demand of Brazil should be approximately 475 six days Curie per week. Since 1995, Brazil regularly acquired ${ }^{99} \mathrm{Mo}$ from the Canadian company MDS NORDION. Therefore, the interruptions that occurred in 2009 in the Canadian NRU reactor caused a 50\% reduction in the nuclear medicine service to the Brazilian population, when compared to the levels of 2008. Slowly over the following years and through agreements with countries such as Belgium, Argentina, South Africa, Israel and the Russian
Federation, it was possible to recover and return to pre-2009 levels and increase to the present state [23], [24]. Considering the regional situation [25], the use of the AHR technology would be attractive to Brazil, as this technology would strengthen the production of medical isotopes for the domestic and export markets.

For example, to meet the ${ }^{99} \mathrm{Mo}$ demand for the current Brazilian market ( 475 six days Curie per week), an AHR would need to work at a thermal power of $100 \mathrm{kWth}$ in operating cycles of 5 days. However, taking into consideration the growth forecasts of $8 \%$ per year, it would be attractive to increase production to around 700 six days Curie per week (estimated demand for 2025), which implies a thermal power of the AHR conceptual design of approximately $142 \mathrm{kWth}$, let's approach that to $150 \mathrm{~kW}$ th [23]. An AHR based on the ARGUS reactor but operating at $150 \mathrm{kWth}$ would have a power density of more than 5 $\mathrm{kWth} /$ liter. At these power density levels the fuel solution is very unstable and susceptible to boiling. In addition, it would entail the need to make major modifications to the ARGUS based heat removal system, in order to dissipate the increase in the heat generated. Therefore, a viable option could be to use two $75 \mathrm{~kW}$ th AHR or three $50 \mathrm{~kW}$ th AHR, for which the power density is much lower. The use of two $75 \mathrm{kWth}$ AHR or three $50 \mathrm{~kW}$ th AHR in order to meet the domestic demand of Brazil will be one of the questions analyzed during the research.

\subsection{ARGUS type AHR conceptual design}

In previous studies [17]-[19], [26], [27], standalone neutronic or thermal-hydraulic calculations of a LEU fuel ARGUS type AHR conceptual design (Figure 2) based on the ARGUS reactor LEU configuration with an uranyl sulfate $\left(\mathrm{UO}_{2} \mathrm{SO}_{4}\right)$ solution [20], [21], [28], have been carried out.

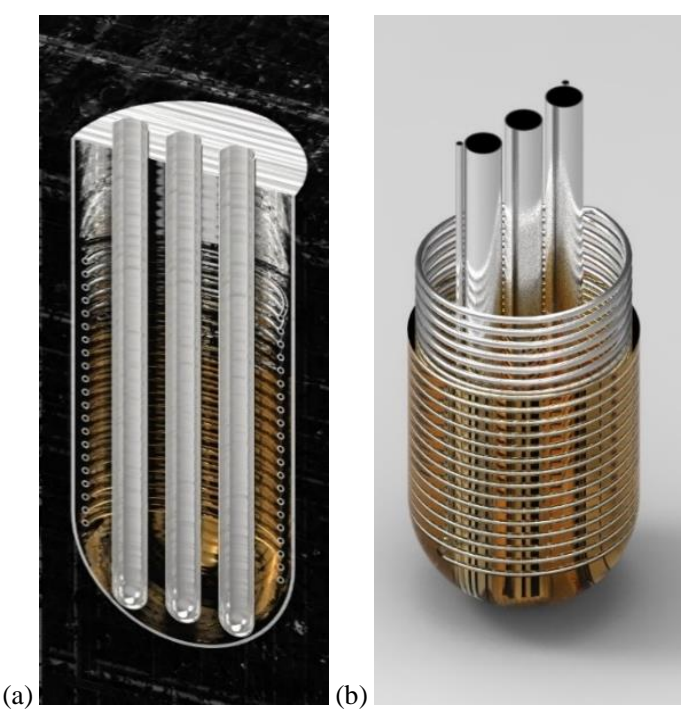

Figure 2. Initial AHR conceptual design model. (a) Longitudinal section of the assembly core. (b) View of vessel's internal parts including the core channels, the coiled cooling pipe, and the fuel solution.

In this paper that conceptual design, which was improved to meet certain regional demand of ${ }^{99} \mathrm{Mo}$, was studied following a coupled multi-physics approach in order to predict its steady state operation. The main modifications made were the thermal power $(75 \mathrm{~kW}$ th or 50 
$\mathrm{kWth}$ ) and the heat removal system which was improved to take into consideration the thermal power increase. The improvements in the heat removal system included modifications in the refrigerant mass flow rate and inlet temperature, and the addition of a second coiled cooling pipe (Figure 3).

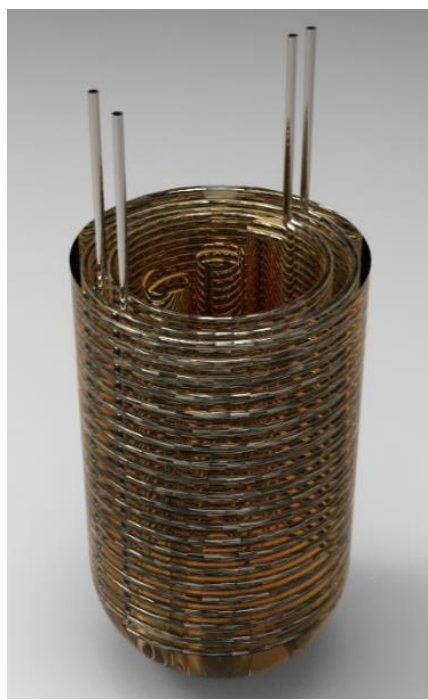

Figure 3. AHR conceptual design model with the two coiled cooling pipes and the fuel solution.

The geometrical conceptual design consists of a stainless-steel cylindrical vessel with a hemispherical bottom filled to a critical state with a low-enriched uranyl sulfate solution. Surrounding the vessel there is a graphite reflector that is horizontally encompassed by a borated polyethylene shield. Placed inside the vessel, there are two coiled-tube heat exchangers and three channels. The central channel has experimental purpose, whereas the other two channels are intended for poison rods. The two coiled-tube heat exchangers use at about $34.5 \mathrm{~m}$ of tubing, $0.60 \mathrm{~cm}$ inner diameter and $1.0 \mathrm{~cm}$ outer diameter. The conceptual design model for the calculation with ANSYS-CFX make an exact representation of the coiled-tube heat exchangers, whereas for the MCNP6 model, the coiled-tube heat exchangers were represented as twenty-one circular torus each, four vertical pipes were included to represent the inlet and outlet pipes. The main reactor core parameters are shown in Table 1.

Table 1. The reactor core parameters.

\begin{tabular}{ll}
\hline Parameter & Value \\
\hline Fuel solution & Uranyl sulfate solution \\
${ }^{235} \mathrm{U}$ enrichment $(\%)$ & 19.8 \\
Uranium concentration $(\mathrm{g} / \mathrm{liter})$ & 380 \\
Inner core diameter $(\mathrm{cm})$ & 30.5 \\
Reactor height $(\mathrm{cm})$ & 65.6 \\
Reactor vessel & Stainless steel \\
Vessel thickness $(\mathrm{cm})$ & 0.5 \\
Reflector (radial) & Graphite $-60 \mathrm{~cm}$ \\
Solution Density $\left(\mathrm{g} / \mathrm{cm}{ }^{3}\right)$ & 1.4950 \\
Fuel solution height $(\mathrm{cm})$ & 52.92 \\
Amount of ${ }^{235} \mathrm{U}$ in the whole reactor $(\mathrm{kg})$ & 2.10 \\
Cold solution volume with no voids & 29.50 \\
(liter) & 50 or 75 \\
Thermal Power $(\mathrm{kWth})$ & 1.70 or 2.54 \\
Power density (kWth/liter of solution) & less than $90{ }^{\circ} \mathrm{C}$ \\
Operating temperature &
\end{tabular}

A distinctive characteristic of the AHRs is the radiolytic decomposition of the water in the aqueous fuel solution. In this process are produced gas bubbles, composed by hydrogen and oxygen in the $\mathrm{UO}_{2} \mathrm{SO}_{4}$ solutions [2]. The production of radiolytic gas bubbles and its influence in the operational behavior of AHR has been previously studied [17]-[19], [29]-[31], and concluded that the production of medical isotopes in solution reactors may not be accomplished without mitigation of its effects [32]. Evaluating the effects produced by radiolytic gas bubble formation require to know two important parameters, (1) the bubble size and (2) the total gas bubbles volume. For the determination of the mature bubble diameter (BD), was used a linear relationship (Eq. 1) developed by [33] using experimental values from [34]-[36].

$B D[\mathrm{~mm}]=0.652 * P D\left[\frac{\mathrm{kW}}{\text { liter }}\right]+0.1099$

As an initial approximation for the total volume of radiolytic gas bubbles produced in the fuel solution was used the model proposed by [32]. Several modification or improvements to this model, proposed by [12], [37], were taken into consideration (Eq. 2).

$V_{B}(t)=\left(1+\frac{1}{\xi}\right) * \frac{G\left(H_{2}\right)}{N_{A}} * \frac{R_{g} T_{g}}{p} * P * t$

Where, $V_{B}$ is the total void volume $\left(\mathrm{cm}^{3}\right), \xi$ is the fraction of $\mathrm{H}_{2}$ molecules per $\mathrm{O}_{2}$ molecule produced by water radiolysis, $G\left(\mathrm{H}_{2}\right)$ is the hydrogen yield in the fuel solution (molecules $\left.\mathrm{eV}^{-1}\right), N_{A}$ is the Avogadro's constant $\left(6.022 * 10^{23}\right.$ $\left.\mathrm{mol}^{-1}\right), T_{g}$ is the void bubble temperature $(\mathrm{K}), R_{g}$ is the gas constant $\left(8.314472 \mathrm{~J} \mathrm{~mol}^{-1} \mathrm{~K}^{-1}\right), p$ is the prerssure inside the reactor vessel $(\mathrm{Pa}), P$ is the reactor power $(\mathrm{W}), t$ is the characteristic time for void bubble release from the fuel solution (s). These parameters' values can be found elsewhere [1], [12], [32], [38], [39]. The characteristic time for void bubble release from the fuel solution was determined as the quotient of half of the fuel solution height (to take into consideration that the majority of bubbles are form near the reactor center) and the bubble's terminal velocity (calculated using the force balance equation for a gas sphere moving through a liquid at constant velocity). Subsequent calculation in the iterative process determined the total volume of radiolytic gas bubbles using the radiolytic gas bubbles average velocity calculated with ANSYS-CFX.

Consequently, the calculated total void volume for the first MCNP calculation was $393.15 \mathrm{~cm}^{3}$ and taking into consideration a thermal expansion of $692.40 \mathrm{~cm}^{3}$ (a variation in the temperature from $20{ }^{\circ} \mathrm{C}$ to $80{ }^{\circ} \mathrm{C}$ was assumed), the fuel solution suffers an increase in the total volume of $1085.55 \mathrm{~cm}^{3}$. Causing a rise in the fuel solution height up to $54.59 \mathrm{~cm}$. Figure 4 shows the geometrical model of the AHR conceptual design on the Visual Editor of the MCNP. As previous calculations carried out with MCNP for a number of bubble sizes and with a model with the bubbles homogenized inside the fuel solution demonstrated that the calculations results are not sensitive to the bubble size [19], the calculation with the MCNP6 code were made with the bubbles homogenized inside the fuel solution. This approximation allows us to reduce considerably the calculation time. 


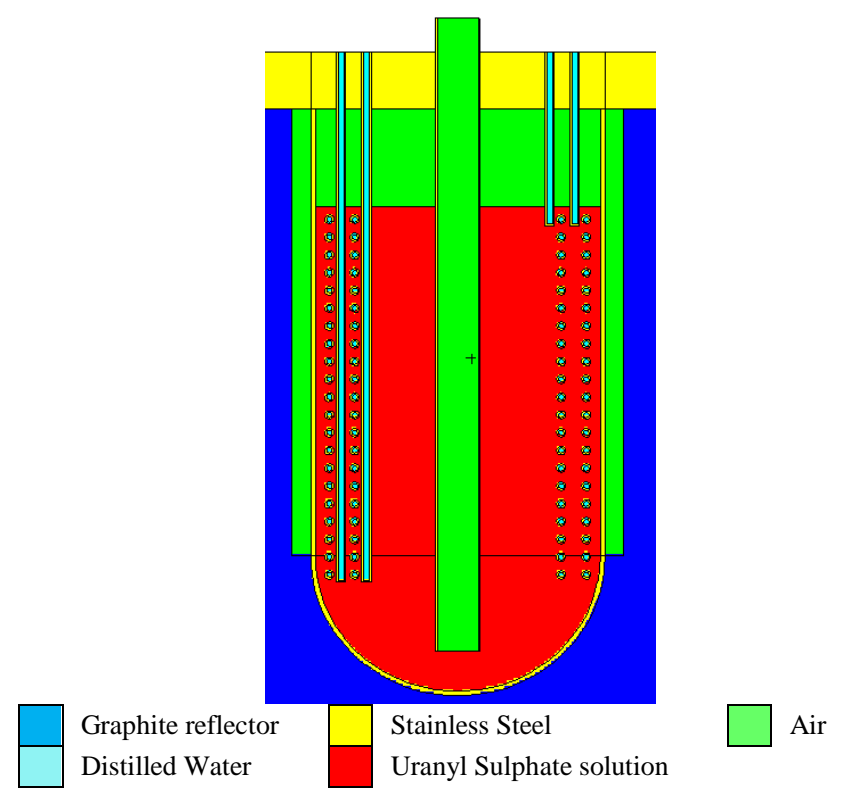

Figure 4. Longitudinal section of the geometrical model of the reactor on the Visual Editor of the MCNP.

Figure 5 shows the geometrical model of the AHR conceptual design and the regions or domains that make up the core of the AHR conceptual design. The selection of computational models, thermal and material properties correlations, meshing, boundary conditions, solution parameters, initial values, libraries and others were made based on previous research. These selections have already been explained and discussed in previous papers [17]-[19].

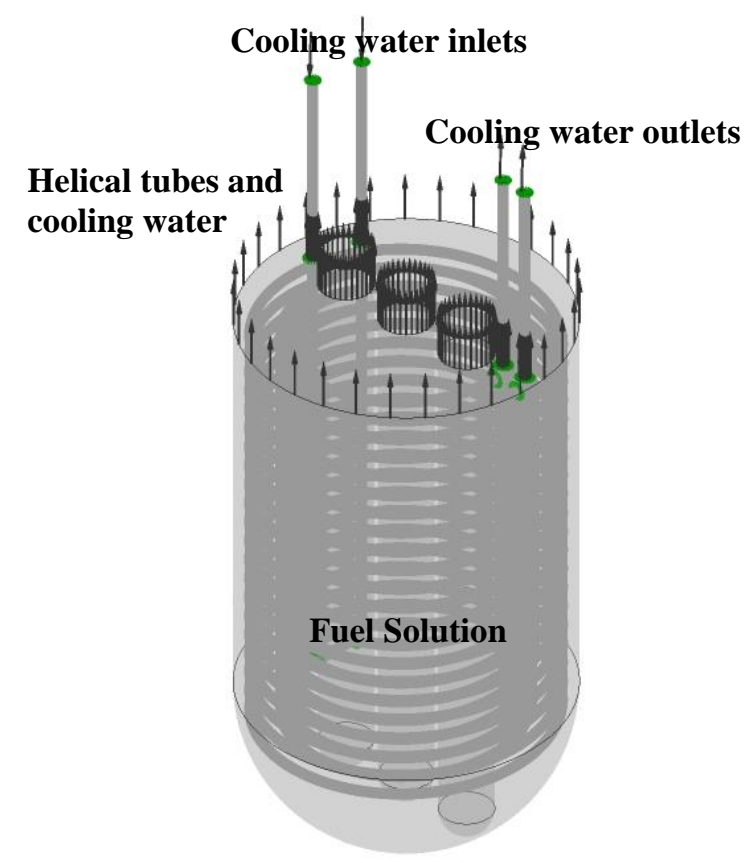

Figure 5. (a) AHR conceptual design and (b) domains of interest for the $C F X$ simulation.

\subsection{Coupling methodology}

As already mentioned, by several years our research group has been working in standalone neutronic and thermalhydraulic calculations of AHRs. Those standalone neutronic and thermal-hydraulic calculations provided us an initial and sufficiently accurate predictive capability about this type of technology. However, if it is taken into consideration the interconnection between the phenomena that occur in these systems, is inevitable the necessity of implement coupled calculations in order to obtain results that can be used for final design steps or the licensing process. The coupling methodology used for the coupled calculations was the following: (1) Define physical, geometrical, material properties and initial operating condition; (2) Run the MCNP code with the initial operating condition to calculate the fission induced energy deposition profile; (3) Obtain the normalized polynomial function that describe the fission induced energy deposition profile and from it obtain the functions for the volumetric energy and gas bubble generation; (4) Run the ANSYS-CFX code with the functions for the volumetric energy and gas bubble generation to calculate the temperature profile, gas bubbles velocity and average fuel solution density; (5) Update the fuel solution density, volume and height in the MCNP input file. Run the new MCNP input file; (6) Continue the coupled calculation (MCNP+ANSYS-CFX) until reaching the convergence of the parameters of interest $(\Delta \leq 1 \%)$. A logical flow chart for the coupling procedure is shown in Figure 6. The most important parameters monitored, for the coupling procedure, were the following:

MCNP: (1) Fission induced energy deposition profile using the flux tally (F4) and the FMESH card (Superimposed Mesh Tally) for a cylindrical mesh.

ANSYS-CFX: (1) Temperature and gas volume fraction profiles in the fuel solution; (2) Liquid and bubbles velocity profiles in the fuel solution; (3) Energy and gas bubbles generation profile; (4) Energy and gas bubbles saturation.

\subsection{Computational platform}

The multi-physics coupled calculations were carried out in two computational clusters, the InSTEC-IRL (operating system: Microsoft Windows 64 bit, 48 cores and 96 GB Memory) and the UFPE-DEN-GER (operating system: Microsoft Windows 64 bit, 64 cores and 152 GB Memory) clusters. As stated previously, the main codes used for the coupled multi-physics calculations were the MCNP6 [40] and ANSYS-CFX 19 [41]. Additional (home-made) codes have been developed for the pre-processing and postprocessing of the main codes.

\section{Testing the methodology for two operating configurations of the ARGUS reactor}

As an important step in the development of the computational methodology, it was tested for two different operating configurations of the ARGUS reactor, the original HEU configuration used since 1981, and the new LEU configuration after the conversion process during 20122014. These studies will fulfill two objectives. First, the assessment of the computational methodology's ability to predict the AHR operating conditions (through comparison with reported temperature values). Second, to demonstrate how the coupled computational methodology allows to obtain results with a higher level of details and precision than those obtained through neutronic and thermal-hydraulic simulations separately. The iterative coupled calculation contemplated in the computational methodology was implemented as described in section 2.3. At the end of each thermal-hydraulic calculation step was checked the convergence of the parameters of interest (fuel solution average temperature, average velocity of the fuel solution and the radiolytic gas bubbles and gas volume fraction in the fuel solution). 


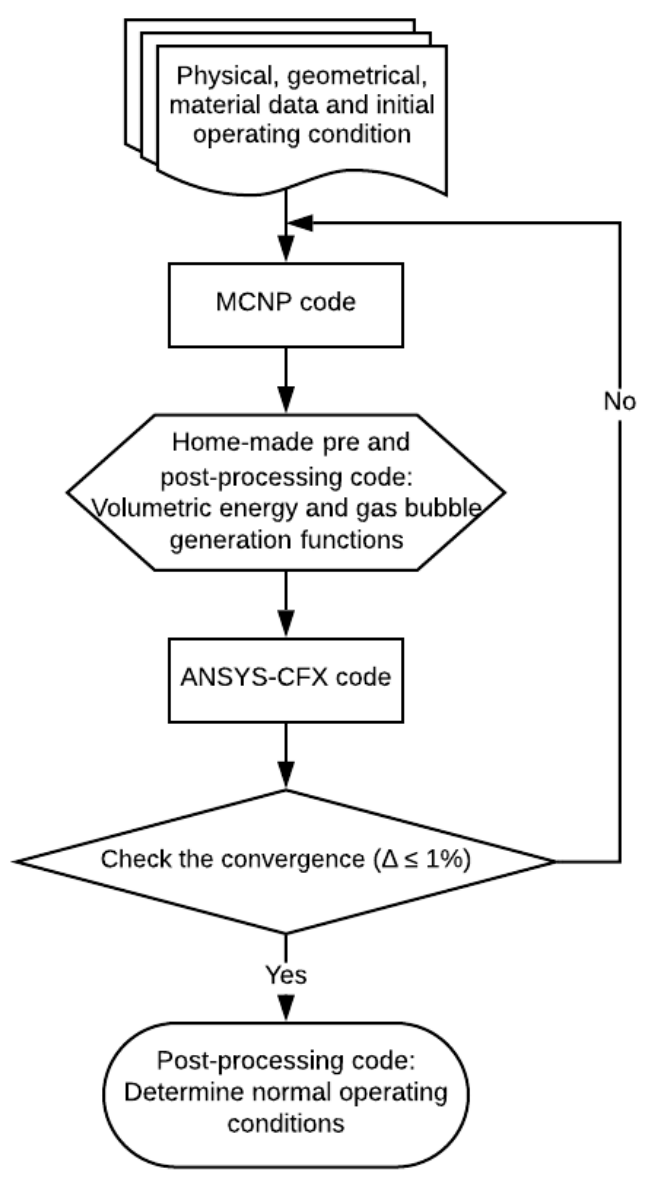

Figure 6. Logical flow chart for the coupling procedure.

Figs. 7 to 10 show the evolution of these parameters of interest with the iterative calculation steps for the two operating configurations of the ARGUS reactor. The convergence of the parameters of interest (relative difference less than or equal to $1 \%$ ) is achieved after four calculation steps except for the fuel solution average temperature that converges after three steps. The difference between the values obtained in the first step (equivalent to an independent and not coupled calculation) and the "converged" values after the fourth step is noteworthy. This contributes to demonstrate how the computational methodology provides results with a higher level of details and precision than those obtained through neutronic and thermal-hydraulic simulations separately.

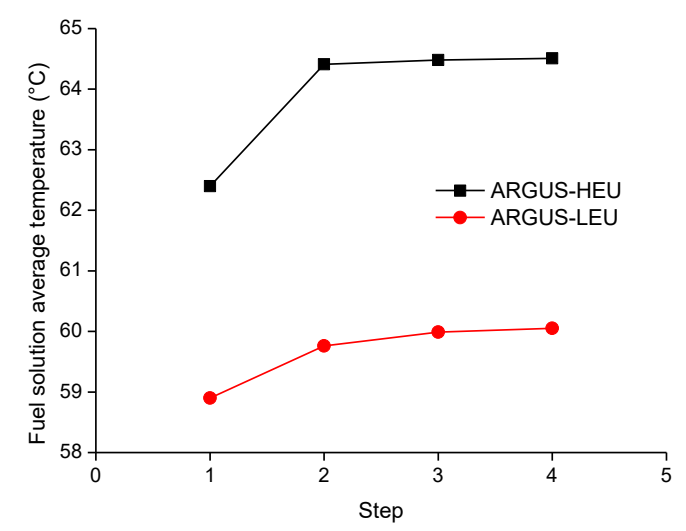

Figure 7. Average fuel solution temperature for the two operating configurations of the ARGUS reactor.

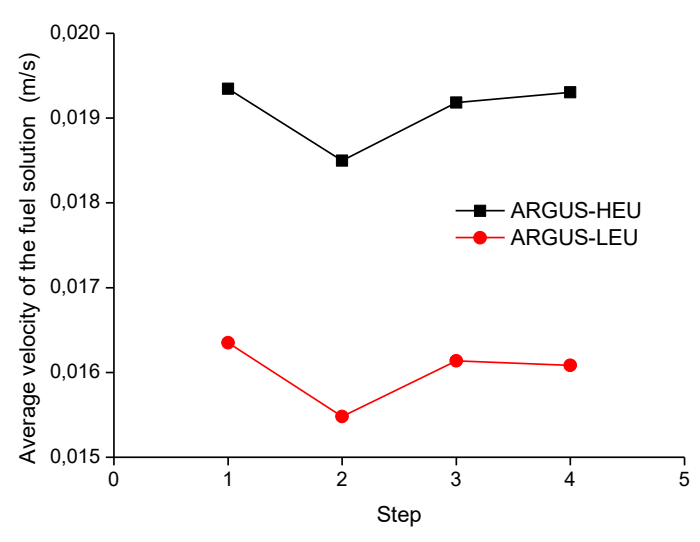

Figure 8. Average fuel solution velocity for the two operating configurations of the ARGUS reactor.

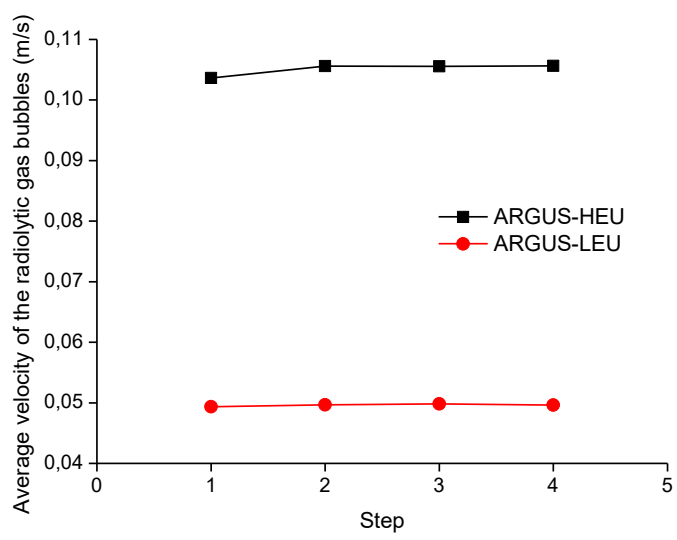

Figure 9. Average radiolytic gas bubbles velocity for the two operating configurations of the ARGUS reactor.

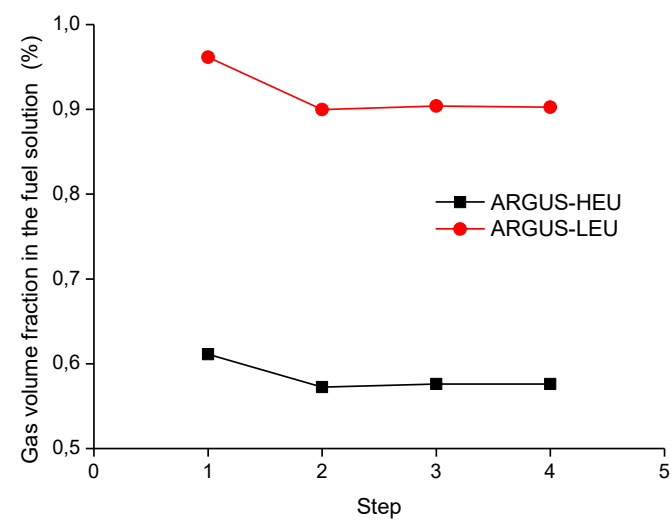

Figure 10. Radiolytic gas volume fraction in the fuel solution for the two operating configurations of the ARGUS reactor.

Figure 11 shows the volumetric distributions of the fuel solution temperature. Figs. 12 and 13 show the velocity profiles of the fuel solution and the radiolytic gas bubbles, respectively. Figure 14 shows the volumetric distributions of the gas volume fraction in the fuel solution. The values obtained for the fuel solution temperature and the cooling water temperature at the outlet are in the temperature range reported in the scientific literature for these systems. Table 2 summarizes these values. 
Table 2. Temperatures results for the two operating configurations of the ARGUS reactor.

\begin{tabular}{|c|c|c|}
\hline Parameter $\left({ }^{\circ} \mathrm{C}\right)$ & $\begin{array}{l}\text { ARGUS- } \\
\text { HEU }\end{array}$ & $\begin{array}{l}\text { ARGUS- } \\
\text { LEU }\end{array}$ \\
\hline Fuel solution average temperature & 64.51 & 60.05 \\
\hline Fuel solution maximum temperature & 76.46 & 77.31 \\
\hline Cooling water average temperature & 42.36 & 38.11 \\
\hline $\begin{array}{l}\text { Cooling water temperature at the } \\
\text { outlet }\end{array}$ & 53.41 & 49.10 \\
\hline
\end{tabular}

(a)
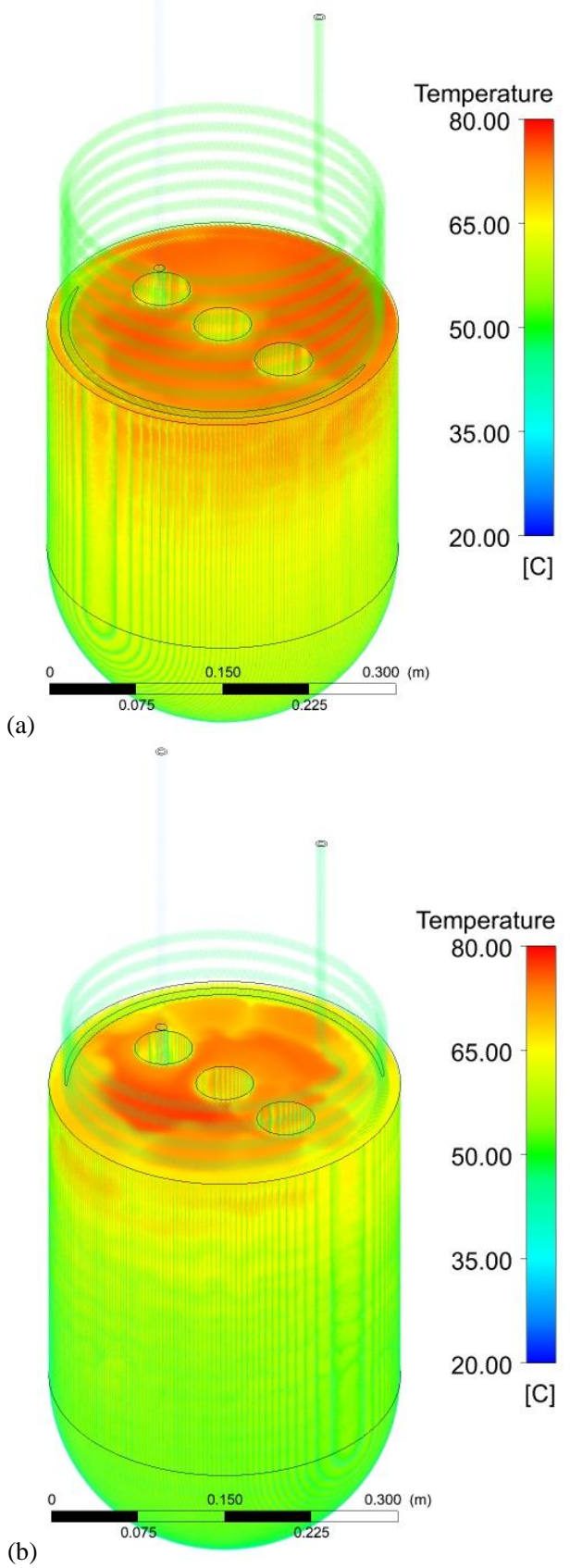

Figure 11. Volumetric distributions of the fuel solution temperature for the two operating configurations of the ARGUS reactor. (a) ARGUS-HEU, (b) ARGUS-LEU.

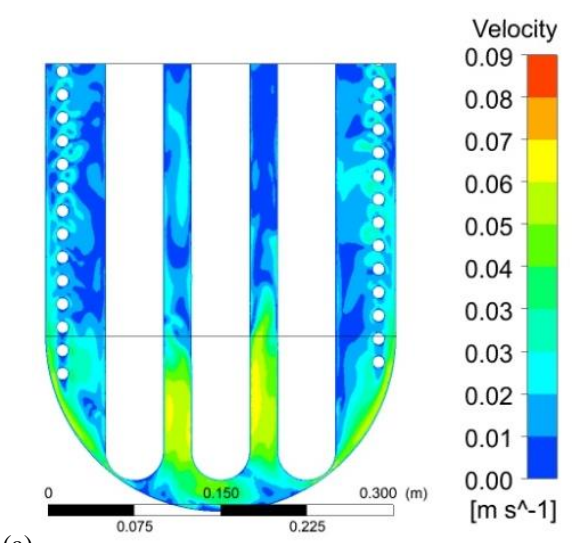

(a)

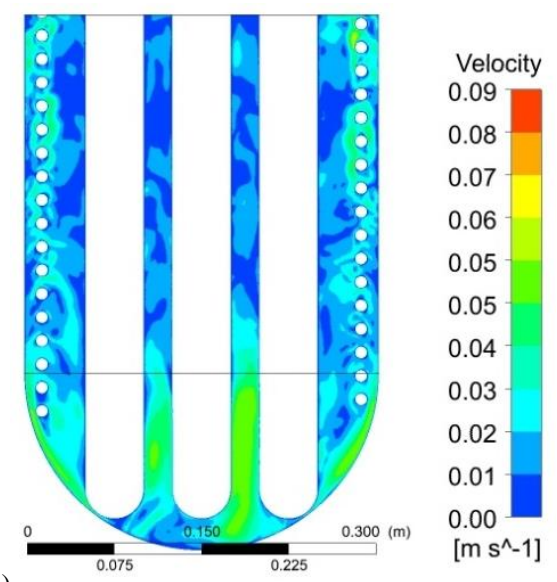

(b)

Figure 12. Velocity profiles of the fuel solution for the two operating configurations of the ARGUS reactor. (a) ARGUS$H E U$, (b) ARGUS-LEU.

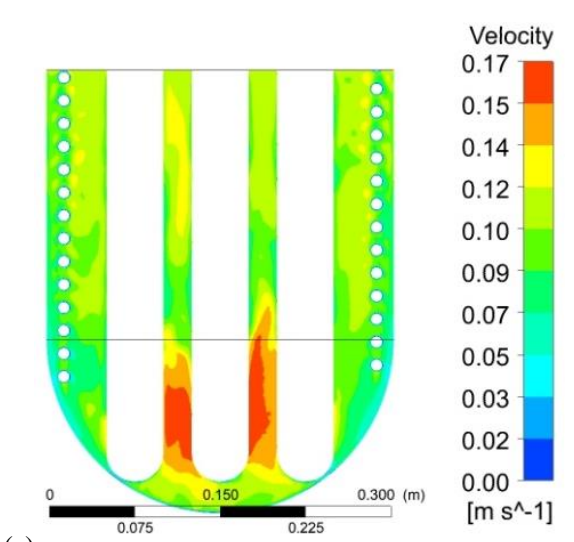

(a)

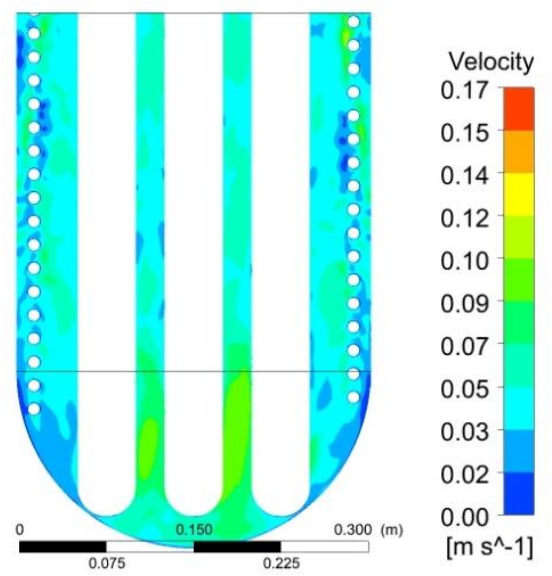

(b)

Figure 13. Velocity profiles of the radiolytic gas bubbles for the two operating configurations of the ARGUS reactor. (a) ARGUS-HEU, (b) ARGUS-LEU. 


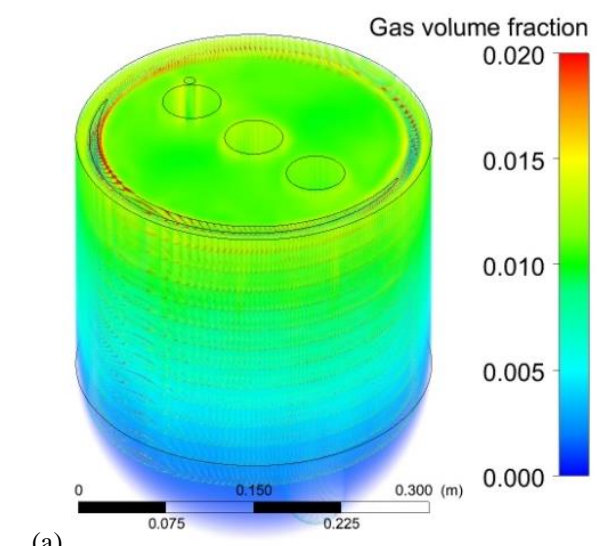

(a)

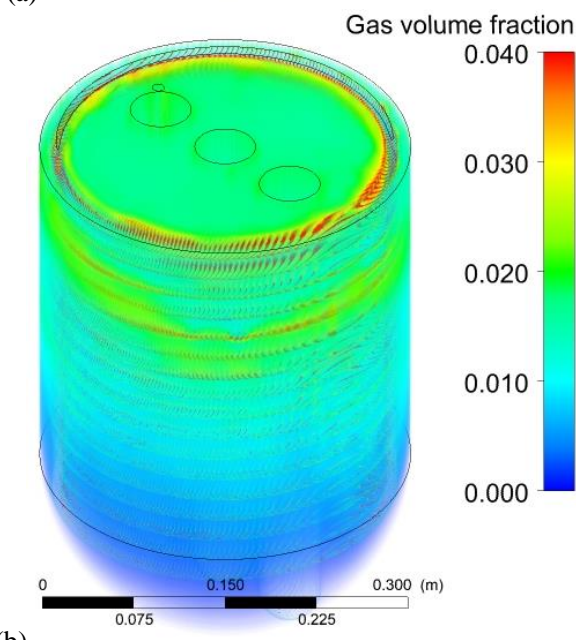

(b)

Figure 14. Volumetric distributions of the radiolytic gas volume fraction in the fuel solution for the two operating configurations of the ARGUS reactor. (a) ARGUS-HEU, (b) ARGUS-LEU.

\section{Results and Discussion}

As discussed in section 2.2, an AHR conceptual design of approximately $150 \mathrm{~kW}$ th should be able to meet the estimated Brazilian ${ }^{99}$ Mo demand for 2025. However, as an AHR conceptual design based on the ARGUS reactor but operating at $150 \mathrm{~kW}$ th would have a power density of more than $5 \mathrm{kWth} / \mathrm{liter}$, it could be advantageous to use two 75 $\mathrm{kWth}$ AHR or three $50 \mathrm{kWth}$ AHR, for which the power density is much lower. In addition, the AHR conceptual design is based on the ARGUS reactor, whose heat removal system was designed for a thermal power of $20 \mathrm{kWth}$ using HEU fuel and $14 \mathrm{kWth}$ using LEU fuel, whereas the conceptual design would operate at a thermal power of 50 $\mathrm{kW}$ th or $75 \mathrm{kWth}$. Therefore, the first of the thermohydraulic studies (before applying the computational methodology) was the design of a new heat removal system that ensures the safe operation of the AHR conceptual design, keeping the fuel solution temperature below $90{ }^{\circ} \mathrm{C}$ to prevent the boiling of the solution. Three alternatives were taken into consideration when redesigning the heat removal system, first decreasing the coolant inlet temperature, second increasing the coolant flow rate and third increasing the heat transfer area. In the first alternative, the coolant inlet temperature was decreased from $25^{\circ} \mathrm{C}$ to $10{ }^{\circ} \mathrm{C}$. In the second alternative, the coolant flow rate was doubled from $0.3 \mathrm{~m}^{3} / \mathrm{h}$ to $0.6 \mathrm{~m}^{3} / \mathrm{h}$. In the third alternative, the number of coiled cooling pipes inside the reactor core was increased from one to two (increasing the heat transfer area by $81.5 \%$ ).
Previous works [17], [18], [26], [27] has dealt with the design and operation of a $75 \mathrm{kWth}$ AHR conceptual design, therefore, that will be the first option to be studied. The volumetric distribution of the fuel solution temperature obtained for the $75 \mathrm{~kW}$ th AHR conceptual design using the ARGUS reactor heat removal system is shown in Figure 15. The maximum temperature achieved by the fuel solution is $204.91{ }^{\circ} \mathrm{C}$, while the average temperature is $178.38{ }^{\circ} \mathrm{C}$. Values well above the permissible temperature criteria. To solve this situation were implemented the three alternatives previously discussed. Figure 16 shows the volumetric distribution of the fuel solution temperature obtained for the $75 \mathrm{~kW}$ th AHR conceptual design with a coolant flow rate of $0.6 \mathrm{~m}^{3} / \mathrm{h}$, a coolant inlet temperature of $10^{\circ} \mathrm{C}$ and two coiled cooling pipes.

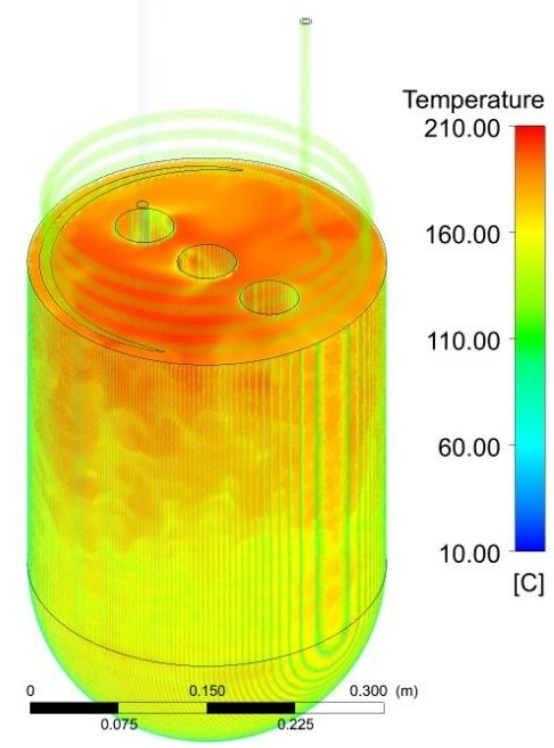

Figure 15. Volumetric distribution of the fuel solution temperature of the $75 \mathrm{kWth}$ AHR conceptual design. Coolant flow rate and temperature $0.3 \mathrm{~m}^{3} / \mathrm{h}$ and $25^{\circ} \mathrm{C}$.

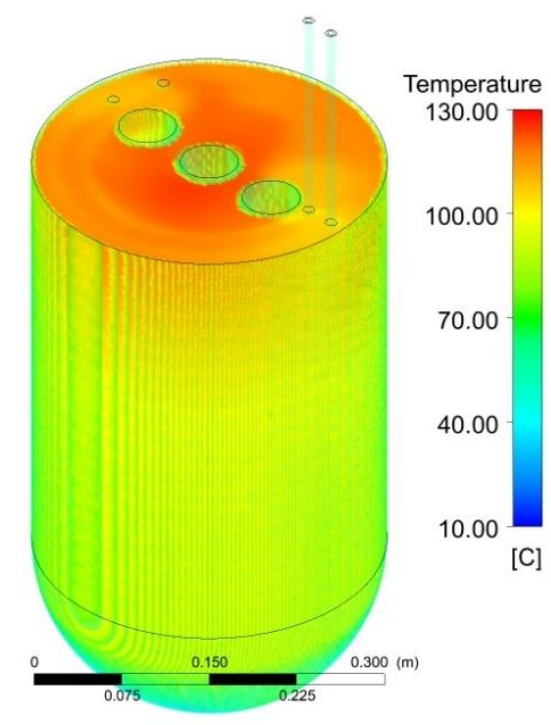

Figure 16. Volumetric distribution of the fuel solution temperature of the $75 \mathrm{kWth}$ AHR conceptual design. Coolant flow rate and temperature $0.6 \mathrm{~m}^{3} / \mathrm{h}$ and $10^{\circ} \mathrm{C}$. 
For this new conceptual design with a coolant flow rate of $0.6 \mathrm{~m}^{3} / \mathrm{h}$, a coolant inlet temperature of $10{ }^{\circ} \mathrm{C}$ and two coiled cooling pipes the maximum and average temperature obtained, $\left(124.44{ }^{\circ} \mathrm{C}\right.$ and $\left.98.65{ }^{\circ} \mathrm{C}\right)$ are still higher than the permissible temperature criteria. One last attempt to use the $75 \mathrm{~kW}$ th AHR conceptual design was made by increasing the coolant flow rate to $1.0 \mathrm{~m}^{3} / \mathrm{h}$. With this new coolant flow rate, the maximum and average temperatures decrease to 115.23 ${ }^{\circ} \mathrm{C}$ and $91.35{ }^{\circ} \mathrm{C}$, respectively. Considering that despite the attempts made the $75 \mathrm{kWth}$ AHR conceptual design continues to maintain temperatures above $90{ }^{\circ} \mathrm{C}$, it was then decided to study the $50 \mathrm{kWth}$ AHR conceptual design.

(a)
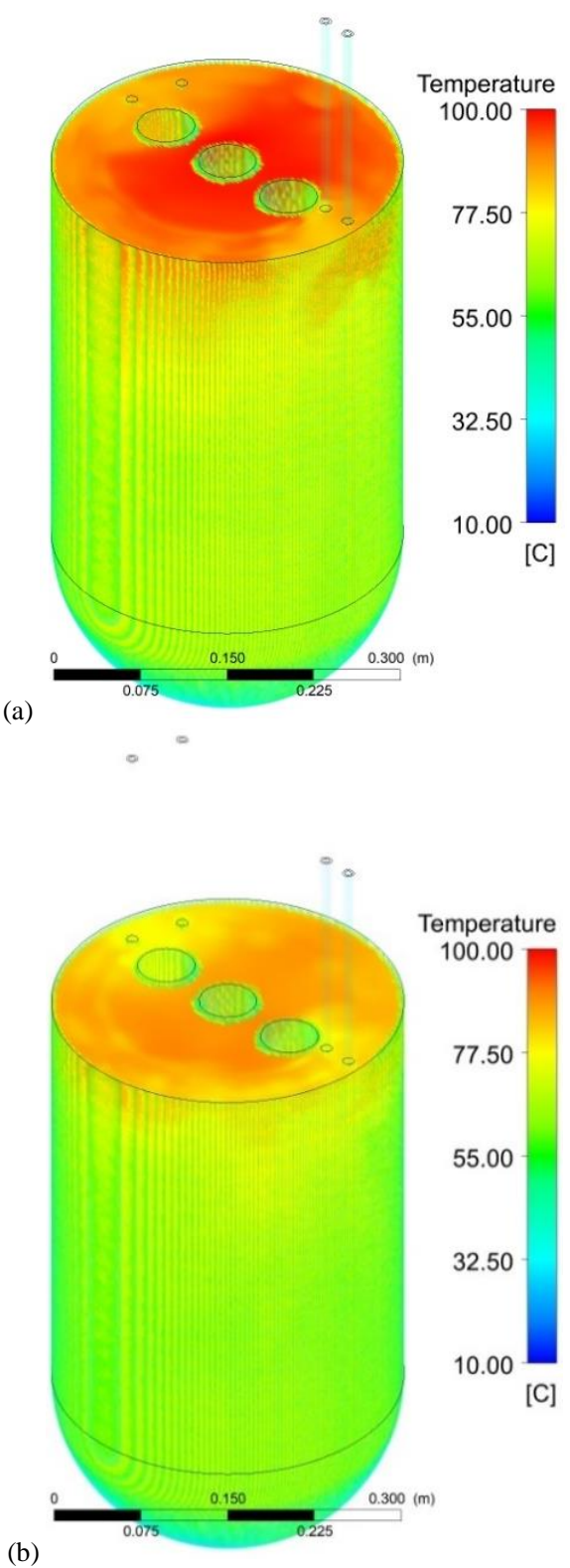

Figure 17. Volumetric distribution of the fuel solution temperature of the $75 \mathrm{kWth}$ AHR conceptual design. Coolant inlet temperature of $10^{\circ} \mathrm{C}$ and two coiled cooling pipes. (a) Coolant flow rate of $0.6 \mathrm{~m}^{3} / \mathrm{h}$, (b) Coolant flow rate of 1.0 $m^{3} / h$.

Figure 17 (a) shows the volumetric distribution of the fuel solution temperature obtained for the $50 \mathrm{kWth}$ AHR conceptual design with a coolant flow rate of $0.6 \mathrm{~m}^{3} / \mathrm{h}$, a coolant inlet temperature of $10{ }^{\circ} \mathrm{C}$ and two coiled cooling pipes. The maximum temperature reached by the fuel solution is $98.14{ }^{\circ} \mathrm{C}$, while the average temperature is 75.84 ${ }^{\circ} \mathrm{C}$, both values are below the water boiling temperature $(100$ $\left.{ }^{\circ} \mathrm{C}\right)$. However, the maximum value is very close to $100{ }^{\circ} \mathrm{C}$, and it is recommended that the temperature should be below $90{ }^{\circ} \mathrm{C}$. Therefore, it was decided to increase the coolant flow rate from $0.6 \mathrm{~m}^{3} / \mathrm{h}$ to $1.0 \mathrm{~m}^{3} / \mathrm{h}$. With that modification, the maximum temperature reached by the fuel solution decreased to $89.42{ }^{\circ} \mathrm{C}$ (Figure 17 (b)). Since the maximum temperature for the $50 \mathrm{~kW}$ th $\mathrm{AHR}$ conceptual design configuration is less than $90{ }^{\circ} \mathrm{C}$, a temperature safety range of at least $10{ }^{\circ} \mathrm{C}$ is ensured, in order to avoid water boiling in the fuel solution.

With the design of the new heat removal system that allows the thermal power of the AHR conceptual design to be increased to $50 \mathrm{kWth}$, ensuring safe operation with the fuel solution temperature below $90{ }^{\circ} \mathrm{C}$, it is now possible to implement the iterative coupled calculation contemplated in the computational methodology to study the steady state operation of the AHR conceptual design. As described in section 2.4, at the end of each thermal-hydraulic calculation step was checked the convergence of the parameters of interest (fuel solution average temperature, average velocity of the fuel solution and the radiolytic gas bubbles and gas volume fraction in the fuel solution). Figs. 18 and 19 show the evolution of these parameters of interest with the iterative calculation steps.

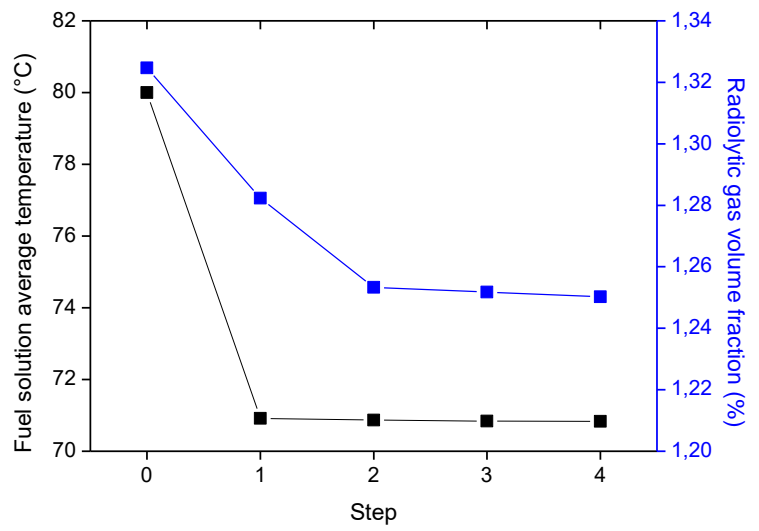

Figure 18. Evolution of the average fuel solution temperature and radiolytic gas volume fraction in the AHR conceptual design.

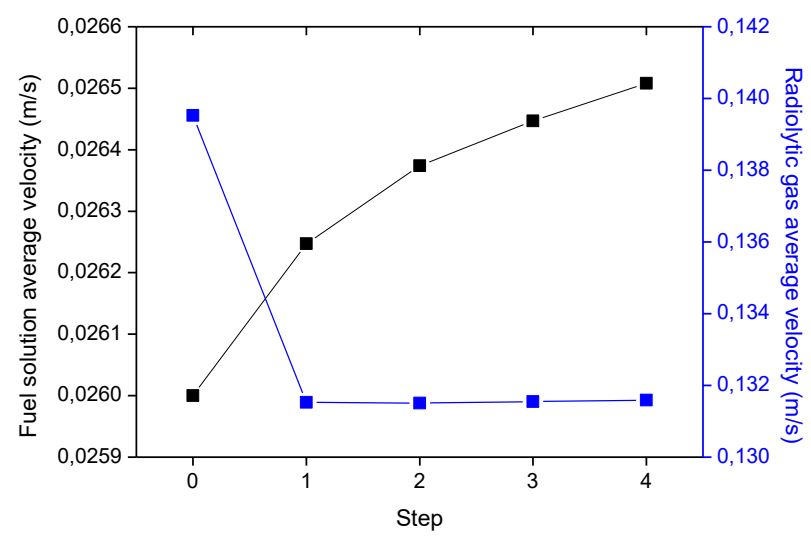

Figure 19. Evolution of the average fuel solution and radiolytic gas velocities in the AHR conceptual design.

The convergence of the parameters of interest (relative difference less than or equal to $1 \%$ ) is achieved after four 
calculation steps. In the four parameters studied, were obtained notable differences between the initial values and the "converged" values after the fourth step. The absolute (and relative differences) obtained between them were 9.17 ${ }^{\circ} \mathrm{C}(11.46 \%)$ for the average temperature, $0.07 \%(5.63 \%)$ for the gas volume fraction, $0.0005 \mathrm{~m} / \mathrm{s}(1.95 \%)$ for the average fuel solution velocity and $0.0079 \mathrm{~m} / \mathrm{s}(5.69 \%)$ for the average radiolytic gas bubbles velocity. These notable differences contribute to demonstrate how the computational methodology provides results with a higher level of detail and precision than those obtained through neutronic and thermal-hydraulic simulations separately. After determining the $50 \mathrm{kWth}$ AHR conceptual design initial steady state operation through the application of the computational methodology, is now possible to study the neutronic and thermal-hydraulic characteristics.

The thermohydraulic studies focused on three fundamental parameters, temperature, velocities and volumetric fractions of the radiolytic gas bubbles and the fuel solution. The purpose of these calculations was to demonstrate that the maximum fuel solution temperature is maintained at all times below $90{ }^{\circ} \mathrm{C}$, which ensures a safe temperature range to prevent boiling of the water present in the fuel solution. First was necessary to obtain the function that describe the volumetric energy and radiolytic gas bubble generation in the AHR conceptual design core. The polynomial function that describe the fission induced energy deposition profile was obtained from in the last MCNP6 calculation. In Figure 20 is shown the fission induced energy deposition profile (for the "converged" state) using the flux tally (F4) and the FMESH card (Superimposed Mesh Tally) for a cylindrical mesh.

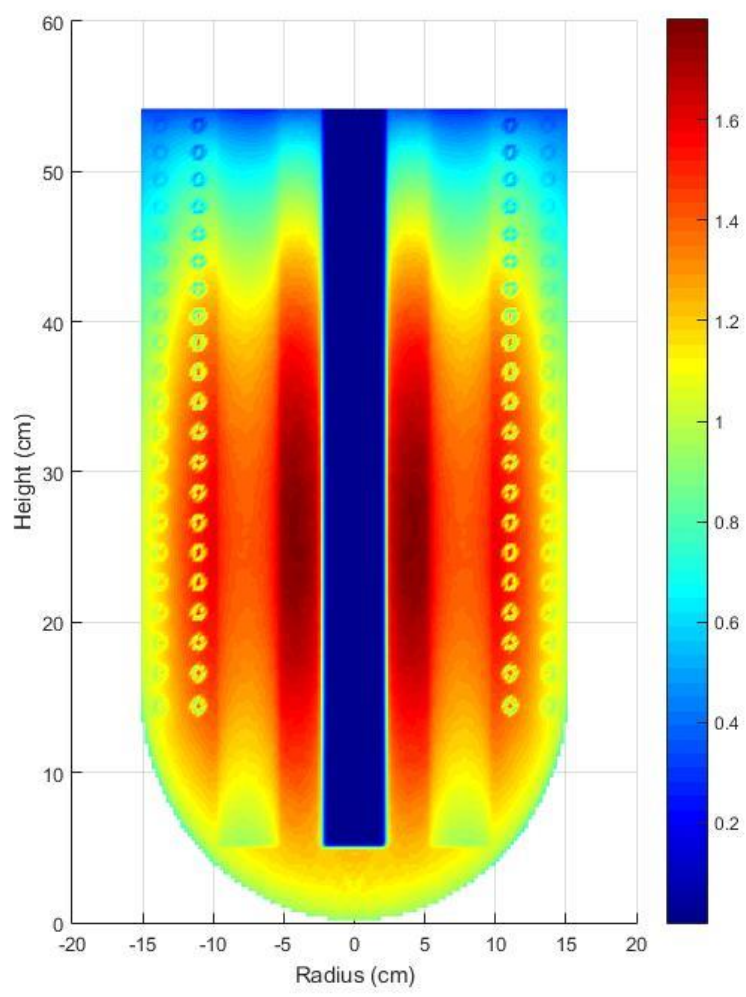

Figure 20. Fission induced energy deposition profile in the AHR conceptual design using the flux tally (F4) and the FMESH card.
Figure 21 shows the volumetric distribution of the fuel solution temperature of the $50 \mathrm{kWth}$ AHR conceptual design. The average temperature of the fuel solution is $70.83{ }^{\circ} \mathrm{C}$, while the maximum temperature is $90.99{ }^{\circ} \mathrm{C}$. Although the maximum temperature value is over $90{ }^{\circ} \mathrm{C}$ by almost 1.00 ${ }^{\circ} \mathrm{C}$, the value is relatively well below the boiling water temperature $\left(100{ }^{\circ} \mathrm{C}\right)$. Figure 22 shows the location of the fuel solution zones with temperatures above $80{ }^{\circ} \mathrm{C}$, while in Figure 23 is shown the fuel solution temperature profiles in the central planes XY and YZ. It is observed that the hottest spots of the fuel solution are located in the upper zone, this behavior is expected, considering that by natural convection the warmer fuel solution rises by density difference and the cooler fuel solution descends to replace it, generating a circular motion.

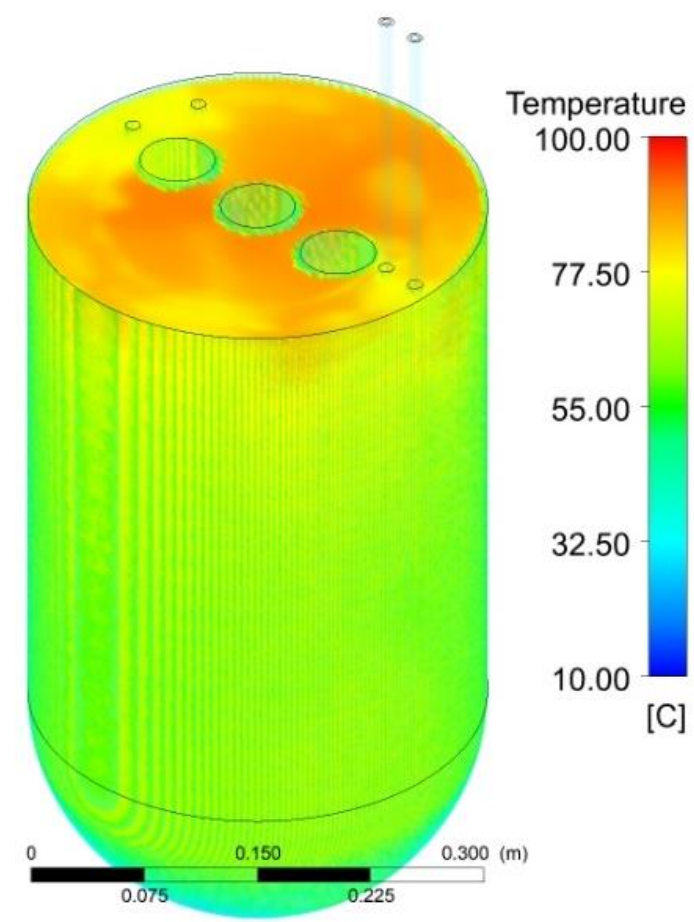

Figure 21. Volumetric distribution of the fuel solution temperature of the $50 \mathrm{kWth}$ AHR conceptual design.

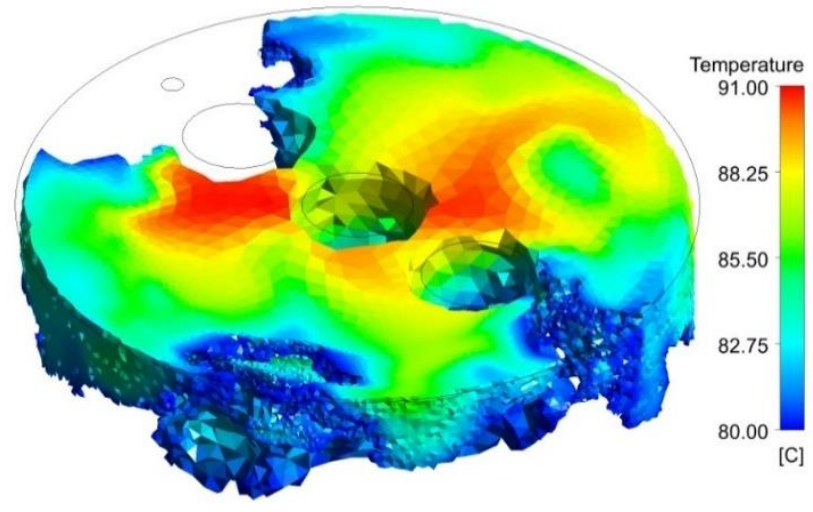

Figure 22. Location of the fuel solution zones with temperatures above $80^{\circ} \mathrm{C}$. 


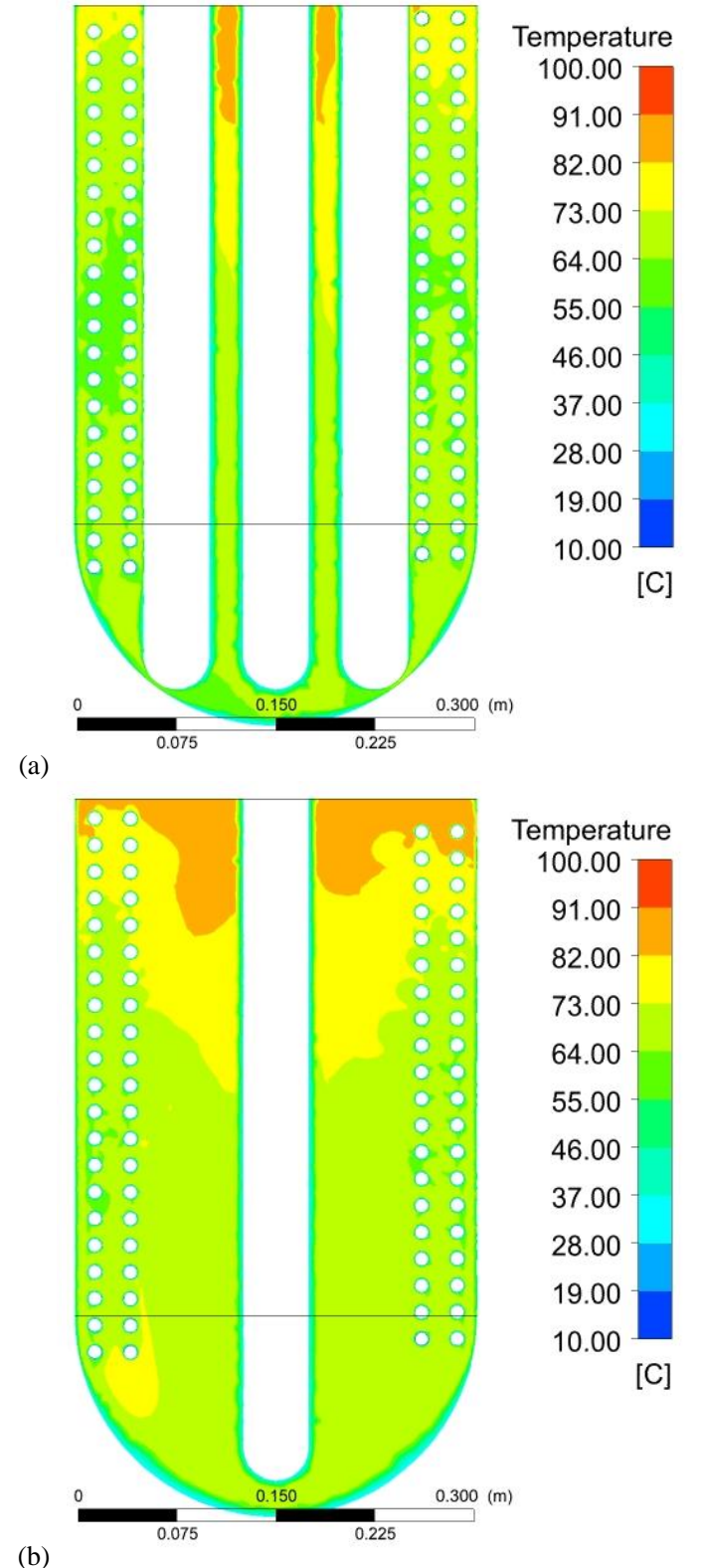

Figure 23. Fuel solution temperature profiles in the central planes $X Y(a)$ and $Y Z(b)$.

The constant movement of the fuel solution, based on density changes due to temperature variations and the upward movement of radiolytic gas bubbles, plays a key role in heat removal from the core. Therefore, the fuel solution and radiolytic gas bubbles velocities are one of the most important magnitudes to be studied. Figs. 24 and 25 show the fuel solution and radiolytic gas bubbles velocity profiles in the central planes XY and YZ, respectively. The average fuel solution and radiolytic gas bubbles velocities are $0.027 \mathrm{~m} / \mathrm{s}$ and $0.132 \mathrm{~m} / \mathrm{s}$, respectively, while the maximum values are $0.107 \mathrm{~m} / \mathrm{s}$ and $0.224 \mathrm{~m} / \mathrm{s}$, respectively. The difference between the fuel solution velocity and the radiolytic gas bubbles velocity is appreciable, the average velocity of the radiolytic gas bubbles is almost five times superior that of the fuel solution, which contributes to reinforce their importance for maintaining the constant movement of the solution. The highest velocity values are concentrated in the central and lower zone. Which contributes to justify why the temperatures in the lower zone are lower compared to the upper zone.
Figure 26 shows the fuel solution and radiolytic gas bubbles streamlines in the $50 \mathrm{~kW}$ th AHR conceptual design. It is observed that the radiolytic gas bubble streamlines have no recirculation, are very linear and upward, whereas the fuel solution streamlines have recirculation in the lower zone and almost no movement in the upper zone. Thus, the heat transfer is greater in the lower zone and lower in the upper zone, justifying the presence of hotter zones in the upper core. Figure 27 shows the volumetric distributions of the radiolytic gas volume fraction in the fuel solution. It is observed how the radiolytic gas bubbles are almost homogeneously distributed in the AHR conceptual design core, with the volumetric fraction in the upper zone being slightly higher from the upward movement of the bubbles. The radiolytic gas bubbles occupy a volume equivalent to $1.25 \%$ of the total volume of the AHR conceptual design core.

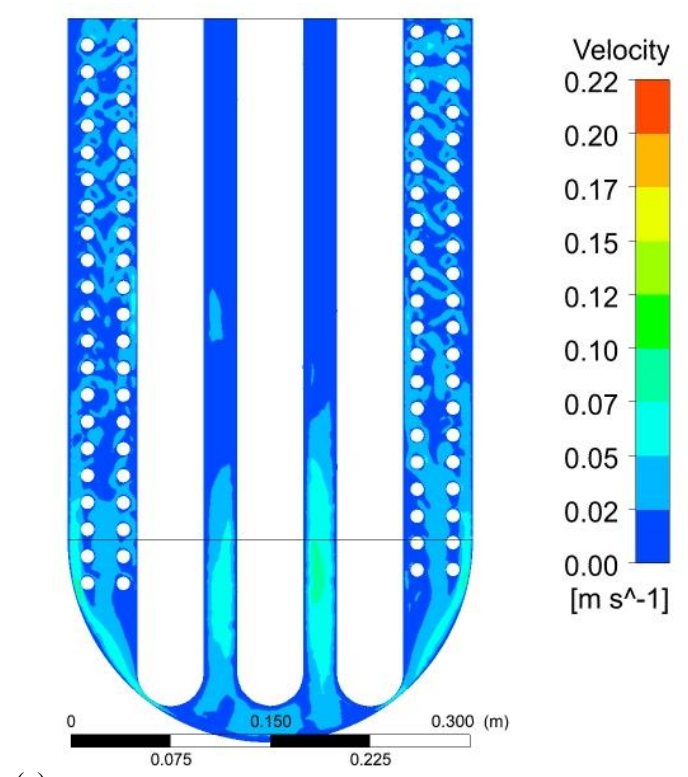

(a)

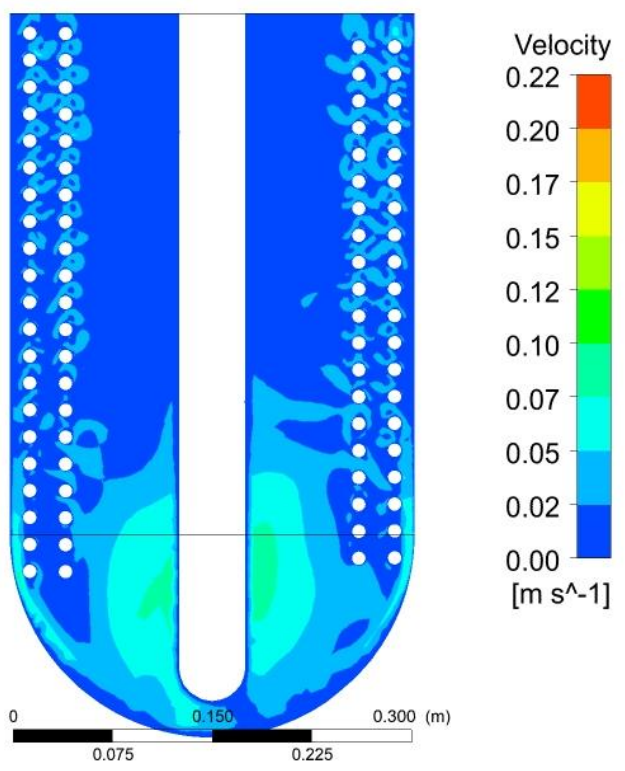

(b)

Figure 24. Fuel solution velocity profiles in the central planes $X Y(a)$ and $Y Z(b)$. 


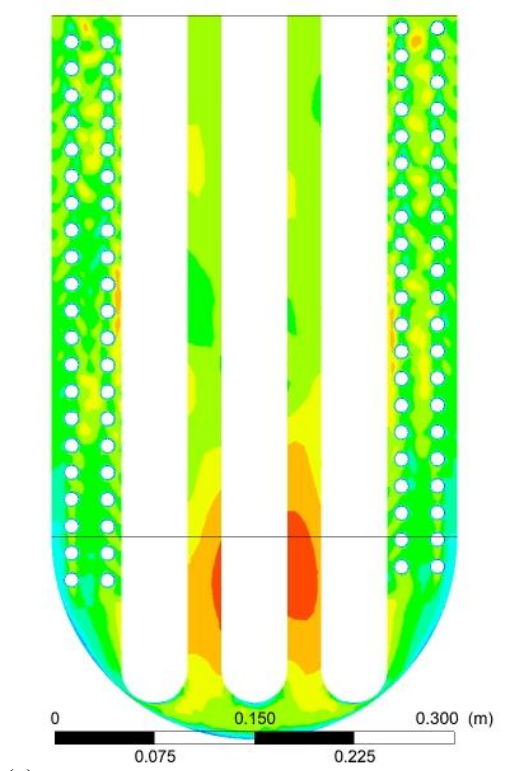

(a)

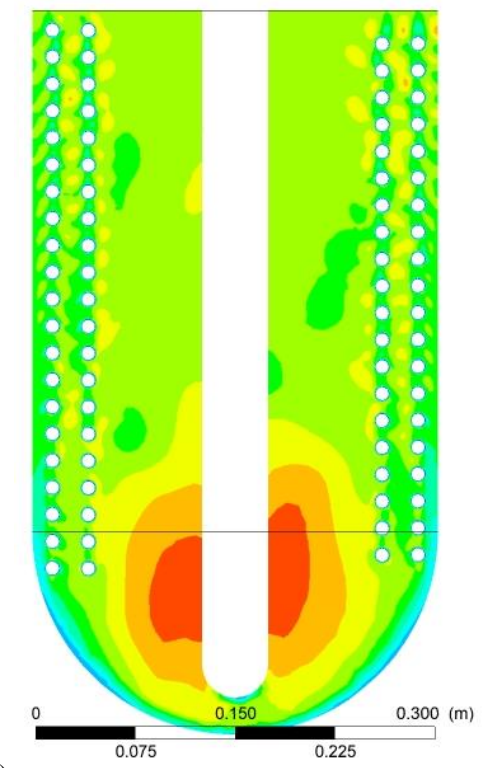

(b)

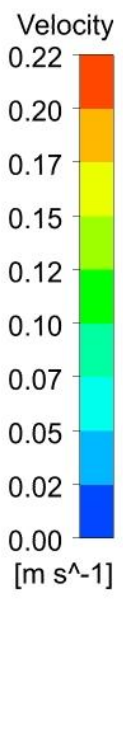

Figure 25. Radiolytic gas bubbles velocity profiles in the central planes $X Y(a)$ and $Y Z(b)$.

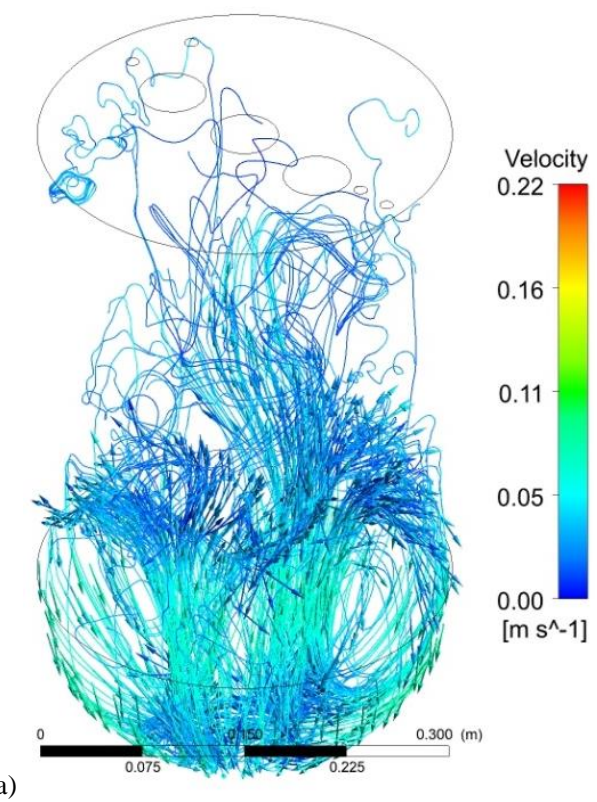

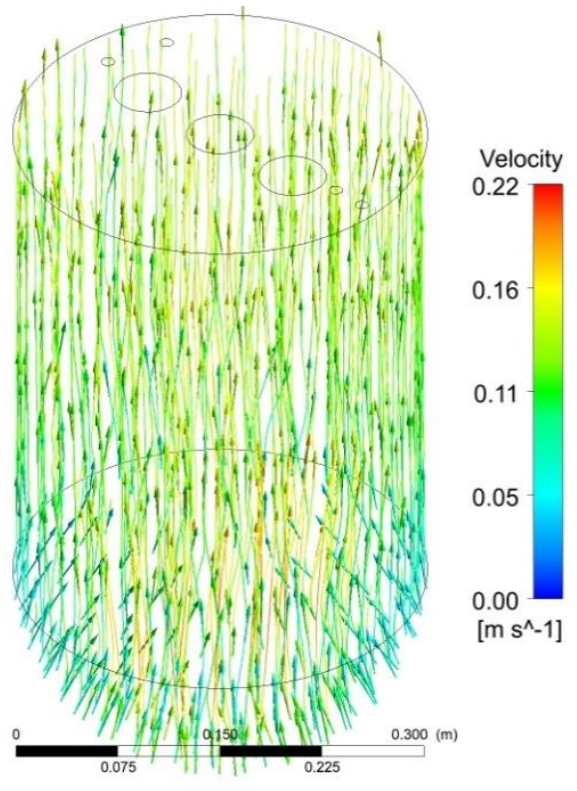

Figure 26. Fuel solution (a) and radiolytic gas bubbles (b) streamlines.

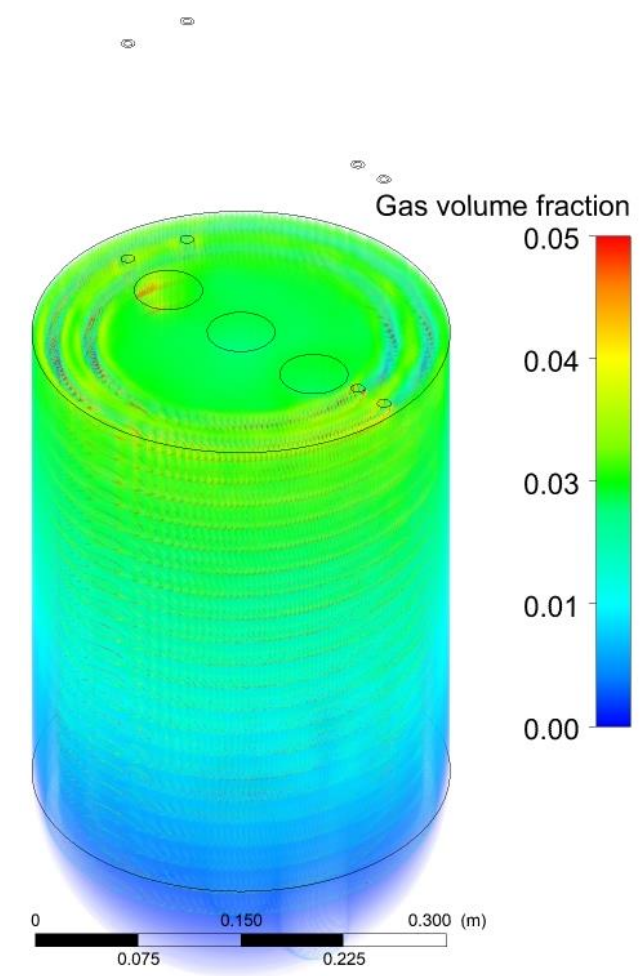

Figure 27. Volumetric distributions of the radiolytic gas volume fraction.

Finally, neutronic calculations were performed to evaluate the proposed AHR conceptual design ability to produce medical isotopes using LEU fuel under safe operating conditions. The neutronic calculations were performed starting from a cold state with fresh fuel. Figure 28 shows the accumulation of the medical isotope ${ }^{99} \mathrm{Mo}$ during 528 hours of operation of the AHR conceptual design. It is observed that the ${ }^{99} \mathrm{Mo}$ inventory, expressed in Curie, grows exponentially until it reaches a saturation activity of 2580 Curie. For this level of production of the medical isotope ${ }^{99} \mathrm{Mo}$, which is provided by the thermal power of the AHR conceptual design, the MCNP code simulation determined that working in five-day operating cycles with two days of cooling and extraction (Figure 29), 
246.5 six days Curie per week of ${ }^{99}$ Mo can be produced. This value is consistent with the estimation made, in which the 50 $\mathrm{kWth}$ AHR conceptual design should produce at least one third of the estimated Brazilian demand for 2025 (700 six days Curie per week of $\left.{ }^{99} \mathrm{Mo}\right)$. Therefore, three $50 \mathrm{kWth}$ AHRs produce 739.5 six days Curie of ${ }^{99} \mathrm{Mo}$, which allows to cover $105.6 \%$ of the estimated Brazilian demand for 2025 .

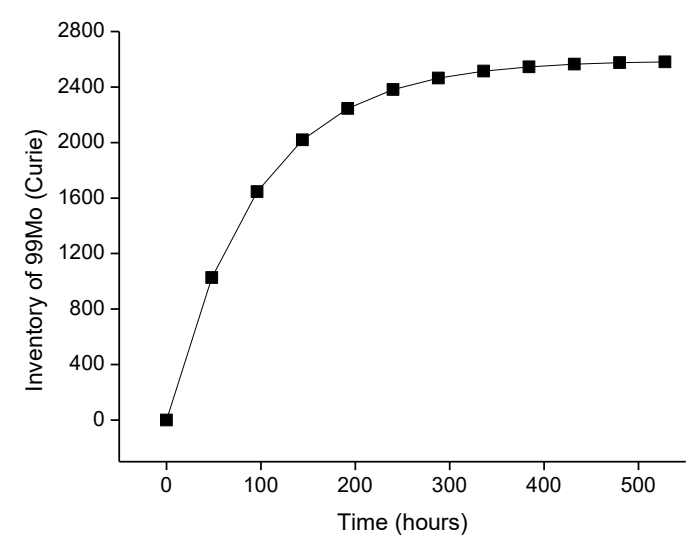

Figure 28. Accumulation of ${ }^{99} \mathrm{Mo}$.

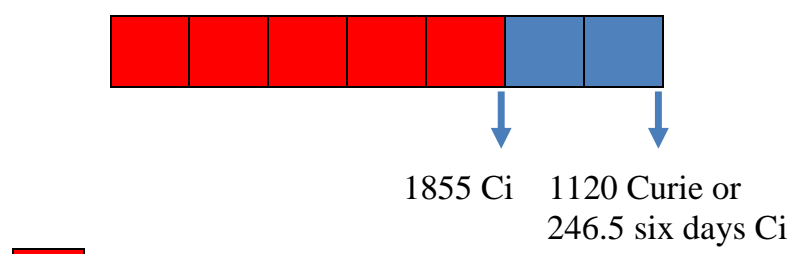

Power operation

${ }^{99}$ Mo extraction (at shut down reactor)

Figure 29. ${ }^{99}$ Mo production schedule.

\section{Conclusions}

The primary objective of this paper is contributing to the analysis of one of the most promising alternatives to produce medical isotopes: the use of Aqueous Homogeneous Reactor. The steady state operation of a low-enriched uranium (LEU) fuel ARGUS type AHR conceptual design for producing ${ }^{99} \mathrm{Mo}$ to meet the domestic demand of Brazil have been studied through a coupled multi-physics evaluation. The methodology followed for the multi-physics and multi-scale coupling of the neutronic and thermalhydraulic codes, which represents one of the main outcomes of the current study, was successfully tested for two different operating configurations of the ARGUS reactor. As a first step in the evaluation, was redesigned the AHR conceptual design heat removal system to ensure safe operation after increasing the reactor thermal power up to $50 \mathrm{kWth}$. Then was implemented the iterative coupled calculation contemplated in the computational methodology. The stopping criterion established for the iterative calculation process was reached after four calculation steps. Resulting in noticeable differences between the initial values and the "converged" values after the fourth step. The thermalhydraulics calculations of the steady state operation of the AHR conceptual design proved that the maximum temperature of the fuel solution is $90.99{ }^{\circ} \mathrm{C}$, although this value is above $90{ }^{\circ} \mathrm{C}$, it is relatively well below the boiling water temperature $\left(100{ }^{\circ} \mathrm{C}\right)$. As expected, the average velocity of radiolytic gas bubbles $(0.132 \mathrm{~m} / \mathrm{s})$ is well above supermeshing method for modelling reactor physics the average velocity of the fuel solution $(0.027 \mathrm{~m} / \mathrm{s})$, which contributes to increasing the constant motion of the fuel solution and thus the heat transfer. Was determined that the average radiolytic gas bubbles volume fraction in the fuel solution is equivalent to $1.25 \%$ of the total volume. The neutronic calculations demonstrated that the reactor is able to produce 246.5 six days Curie of ${ }^{99} \mathrm{Mo}$ in operation cycles of five days. This is equivalent to more than a third of the estimated Brazilian demand for 2025 (700 six days Curie per week of ${ }^{99} \mathrm{Mo}$ ). Thus, three $50 \mathrm{~kW}$ th AHRs produce 739.5 six days Curie per week of ${ }^{99} \mathrm{Mo}$, which allows to cover $105.6 \%$ of the estimated Brazilian demand for 2025 .

\section{Acknowledgements:}

This research was partially supported by the Conselho Nacional de Desenvolvimento Científico e Tecnológico do Brasil (CNPq), project no: 141270/2016-0.

\section{Nomenclature \\ AHR Aqueous Homogeneous Reactor \\ $\mathrm{Ci} \quad$ Curie \\ CRP Coordinated Research Project \\ HEU Highly Enriched Uranium \\ HFR High Flux Reactor \\ InSTEC- Higher Institute of Technologies and \\ IRL Applied Sciences - Internet Reactor \\ Laboratory \\ LEU Low Enriched Uranium \\ NRU National Research Universal \\ UFPE- Reactor Engineering Group of the Nuclear \\ DEN-GER Energy Department of the Federal University of Pernambuco}

\section{References:}

[1] IAEA, "Homogeneous Aqueous Solution Nuclear Reactors for the Production of Mo-99 and other Short Lived Radioistotopes," Vienna, 2008.

[2] J. A. Lane, "AQUEOUS HOMOGENEOUS REACTORS," in Fluid Fuel Reactors, Oak Ridge, 1962 , p. 30.

[3] IAEA, "Research Reactor Database (RRDB)," 2020. [Online].

Available: https://nucleus.iaea.org/RRDB/RR/ReactorSearch.a spx?filter=0. [Accessed: 28-May-2020].

[4] IAEA, "IAEA Coordinated Research Project (CRP) Feasibility Evaluation of the Use of Low Enriched Uranium Fuelled Homogeneous Aqueous Solution Nuclear Reactors for the Production of Short Lived Fission Product Isotopes," Vienna, 2010.

[5] NEA, "The Supply of Medical Radioisotopes Results from the Third Self-assessment of the Global Mo-99/Tc-99m Supply Chain," Paris, 2017.

[6] NEA, "The Supply of Medical Radioisotopes 2018 Medical Isotope Demand and Capacity Projection for the 2018-2023 Period," Paris, 2018.

[7] NEA, "The Supply of Medical Radioisotopes. 2019 Medical Isotope Demand and Capacity Projection for the 2019-2024 Period," 2019.

[8] A. G. Buchan et al., "Simulated transient dynamics and heat transfer characteristics of the water boiler nuclear reactor - SUPO - with cooling coil heat extraction," Ann. Nucl. Energy, vol. 48, pp. 68-83, Oct. 2012.

[9] A. G. Buchan et al., "The immersed body problems with complex internal structures," Ann. 
Nucl. Energy, vol. 63, pp. 399-408, Jan. 2014.

[10] A. J. Youker, S. D. Chemerisov, M. Kalensky, P. Tkac, D. L. Bowers, and G. F. Vandegrift, "A Solution-Based Approach for Mo-99 Production: Considerations for Nitrate versus Sulfate Media," Sci. Technol. Nucl. Install., vol. 2013, pp. 1-10, 2013.

[11] A. J. Youker, D. C. Stepinski, L. Ling, and G. F. Vandegrift, "Mo Recovery Updates and Physical Properties of Uranyl Sulfate Solutions," Argonne, 2014.

[12] C. M. Cooling, M. M. R. Williams, E. T. Nygaard, and M. D. Eaton, "The application of polynomial chaos methods to a point kinetics model of MIPR: An Aqueous Homogeneous Reactor," Nucl. Eng. Des., vol. 262, pp. 126-152, Sep. 2013.

[13] C. M. Cooling, M. M. R. Williams, E. T. Nygaard, and M. D. Eaton, "An extension of the point kinetics model of MIPR to include the effects of pressure and a varying surface height," Ann. Nucl. Energy, vol. 72, pp. 507-537, Oct. 2014.

[14] P. H. Liem, H. N. Tran, and T. M. Sembiring, "Design optimization of a new homogeneous reactor for medical radioisotope Mo-99/Tc-99m production," Prog. Nucl. Energy, vol. 82, pp. 191196, Jul. 2015.

[15] Z. Gholamzadeh, S. A. H. Feghhi, S. M. Mirvakili, A. Joze-Vaziri, and M. Alizadeh, "Computational investigation of $99 \mathrm{Mo}, 89 \mathrm{Sr}$, and $131 \mathrm{I}$ production rates in a subcritical UO2(NO3)2 aqueous solution reactor driven by a $30-\mathrm{MeV}$ proton accelerator," Nucl. Eng. Technol., vol. 47, no. 7, pp. 875-883, Dec. 2015.

[16] S. M. Mirvakili, Z. Gholamzadeh, and A. Davari, "Neutronic and thermo hydraulic analysis of a modeled subcritical uranyl nitrate aqueous reactor driven by $30-\mathrm{MeV}$ protons," Ann. Nucl. Energy, vol. 97, pp. 171-178, Nov. 2016.

[17] D. M. Pérez et al., "Thermal-Hydraulics Study of a $75 \mathrm{~kW}$ th Aqueous Homogeneous Reactor for $99 \mathrm{Mo}$ Production," J. Thermodyn., vol. 2015, pp. 1-11, 2015.

[18] D. M. Pérez, D. E. M. Lorenzo, C. A. B. De Oliveira Lira, C. R. G. Hernández, M. C. Rodríguez, and L. P. R. Garcia, "Effects of some calculation parameters on the computational modelling of temperature, velocity and gas volume fraction during steady-state operation of an aqueous homogeneous reactor," Int. J. Nucl. Energy Sci. Technol., vol. 11, no. 1, p. 1, 2017.

[19] D. M. Pérez, D. E. M. Lorenzo, C. A. B. de Oliveira Lira, and L. P. R. Garcia, "Neutronic evaluation of the steady-state operation of a $20 \mathrm{kWth}$ Aqueous Homogeneous Reactor for Mo-99 production," Ann. Nucl. Energy, vol. 128, 2019.

[20] S. V Myasnikov, A. K. Pavlov, N. V Petrunin, and V. A. Pavshook, "Conversion of the ARGUS Solution Reactor to LEU Fuel : Results of Feasibility Studies and Schedule," in RERTR 2012 - 34th International Meeting on Reduced Enrichment for Research and Test reactors, 2012, p. 8.

[21] P. P. Boldyrev, V. S. Golubev, S. V. Myasnikov, A. K. Pavlov, N. V. Petrunin, and V. A. Pavshook, "The Russian ARGUS Solution Reactor HEU-LEU London, 2014.
Conversion: LEU Fuel Preparation, Loading and First Criticality," in RERTR 2014 - 35th International Meeting on Reduced Enrichment for Research and Test reactors, 2014, p. 8.

[22] A. Vakulenko, "ROSATOM's vision of Russia's role in global molybdenum-99 supply," Vienna, 2017.

[23] CNEN, "RELATÓRIO DE GESTÃO DO EXERCÍCIO DE 2017,” RIO DE JANEIRO, 2018.

[24] CNEN, "RELATÓRIO DE GESTÃO DO EXERCÍCIO DE 2015,” Rio de Janeiro, 2016.

[25] IAEA, "ARCAL Perfil Estratégico Regional para América Latina y el Caribe (PER) 2016 -2021," Vienna, 2015.

[26] D. M. Pérez, "Diseño conceptual de un AHR de 75 kWt que utiliza combustible LEU para la producción de isótopos médicos," Instituto Superior de Tecnologías y Ciencias Aplicadas, La Habana, 2015.

[27] D. M. Pérez, D. E. M. Lorenzo, C. A. Brayner, D. O. Lira, and L. P. R. Garcia, "NEUTRONIC AND THERMAL-HYDRAULIC STUDIES OF AQUEOUS HOMOGENEOUS REACTOR FOR MEDICAL ISOTOPES PRODUCTION," in International Nuclear Atlantic Conference - INAC 2017, 2017, vol. 99, p. 22.

[28] E. S. Glouchkov and V. E. Khvostionov, "Graphitereflected uranyl sulphate $(20.9 \% 235 \mathrm{U})$ solutions," Moscow, 1997.

[29] Y. Li et al., "FMSR: A code system for in-core fuel management calculation of aqueous homogeneous solution reactor," Nucl. Eng. Des., vol. 240, no. 4, pp. 763-770, 2010.

[30] C. C. Pain, C. R. E. De Oliveira, A. J. H. Goddard, and A. P. Umpleby, "Non-linear space-dependent kinetics for the criticality assessment of fissile solutions," Prog. Nucl. Energy, vol. 39, no. 1, pp. 53-114, 2001.

[31] F. Barbry, "French solution reactor experience and contribution to the Feasibility of the Use of LEU Fuelled Homogenous Aqueous Solution Nuclear Reactors for the Production of Short Lived Fission Product Isotopes," Vienna, 2010.

[32] F. J. Souto, R. H. Kimpland, and A. S. Heger, "Analysis of the Effects of Radiolytic-Gas Bubbles on the Operation of Solution Reactors for the Production of Medical Isotopes," Nucl. Sci. Eng., vol. 150 , no. 3, pp. 322-335, 2005.

[33] A. J. Wass, "Supo Thermal Model Development II," Los Alamos, 2017.

[34] L. D. P. King, "Design and Description of Water Boiler Reactors," in International Conference Peaceful Uses Atomic Energy, 1955, vol. 5, no. 32, pp. 372-391.

[35] M. E. Bunker, "Status Report on the Water Boiler Reactor," Los Alamos, 1963.

[36] S. Chemerisov et al., "Experimental Results for Direct Electron Irradiation of a Uranyl Sulfate Solution: Bubble Formation and Thermal Hydraulics Studies," Argonne, 2015.

[37] C. M. Cooling, "Development of a Point Kinetics Model with Thermal Hydraulic Feedback of an Aqueous Homogeneous Reactor for Medical Isotope Production,” Imperial College London,

F. J. Souto and A. S. Heger, "A Model to Estimate 
Volume Change due to Radiolytic Gas Bubbles and Thermal Expansion in Solution Reactors," Los Alamos, 1996.

[39] F. J. Souto and R. H. Kimpland, "Reactivity analysis of solution reactors for medical-radioisotope production," Nucl. Instruments Methods Phys. Res. Sect. B Beam Interact. with Mater. Atoms, vol. 213, no. 3, pp. 369-372, 2004.
[40] Los Alamos National Laboratory, "MCNP6.1/MCNP5/MCNPX User Manual." Los Alamos National Laboratory, Los Alamos, p. 1001, 2013.

[41] ANSYS Team, “ANSYS CFD 19.0 Documentation, User's Guide manual,” 2019. [Online]. Available: http://www.ansys.com. [Accessed: 01-Jul-2019]. 